\title{
Sagittal and Partial Coronal Synostosis, Treated by Modified Pi Procedure with Barrel Stave Osteotomy : Report of One Case
}

\author{
Haque $\mathbf{M}^{1}$, Mahbub $\mathrm{AA}^{2}$, Islam $\mathrm{KMT}^{3}$, Sharif $\mathrm{S}^{4}$, Halder $\mathrm{R}^{5}$, Hossain $\mathrm{ATMM}^{6}$ \\ Conflict of interest: There is no conflict \\ of interest relevant to this paper to \\ disclose. \\ Funding Agency : was not funded by \\ any institute or any group. \\ Contribution of Authors:

\begin{abstract}
Craniosynostosis consists ofprematurefusion of cranial suture(s) resulting inabnormal head shape. Sagittal craniosynostosis involves premature closure ofthe sagittal suture, producing an abnormallyelongated skull called scaphocephaly. Multiple techniques and their modifications have been used forthe correction of sagittal craniosynostosis. We present a case of sagittal and partial coronal craniosynostosis who was treated with Modified Piprocedure with barrel stave osteotomy.
\end{abstract}

Principal Investigator - Dr. Moududul Haque

Data collection- Dr. Abdullah Al Mahbub, Manuscript preparation- Dr. KM Tarikul Islam, Dr.Sujan Sharif, Dr. Rathin Halder

Editorial formatting- Prof. ATM Moshare Hossain

Copyright: @2020bang.BJNS published by BSNS. This article is published under the creative commons CC-BY-NC license. This license permits use distribution (https://creativecommons .orgf/licences/by-nc/4-0/)reproduction in any medium, provided the original work is properly cited and is not used for commercial purposes.

Received: 3 February, 2019

Accept: 2 July, 2019

\section{Introduction:}

Prematurefusion ofa cranial suture is called craniosynostosis.

Nonsyndromicsynostosis tends to comprise the majority of the cases of craniosynostosis (1 in 2,500), ${ }^{1}$ more commonlyinvolvesone suture, and occurs sporadically in the population. Syndromic craniosynostosis occurs in conjunction with certain syndromic presentations in children.
Key Words: scaphocephaly, sagittal craniosynostosis, Modified Pi technique

Bang. J Neurosurgery 2020; 9(2): 151-155

The classification of the craniosynostosis is based on either the suture(s) involved or the shape of the head. Sagittal craniosynostosis is the most common type affecting a single suture. It usually results in dolichocephaly orscaphocephaly (boat shaped skull) ${ }^{2}$ with frontal bossing, prominent occiput, palpable keellike sagittal ridge. OFC remains close to normal, but the biparietal diameter is markedly reduced.

Multiple methods of surgical repair have been described, from strip craniectomies to extensive

1. Dr. Moududul Haque, Associate Professor, Department of Neurosurgery, Bangabandhu Sheikh Mujib Medical University

2. Dr. Abdullah Al Mahbub, Resident, Department of Neurosurgery, Bangabandhu Sheikh Mujib Medical University.

3. Dr. KM Tarikul Islam, Associate Professor, Department of Neurosurgery, Bangabandhu Sheikh Mujib Medical University

4. Dr. Sujan Sharif, Resident, Department of Neurosurgery, Bangabandhu Sheikh Mujib Medical University

5. Dr. Rathin Halder, Resident, Department of Neurosurgery, Bangabandhu Sheikh Mujib Medical University

6. ATM Mosharef Hossain, Professor and Chairman, Department of Neurosurgery, Bangabandhu Sheikh Mujib Medical University Address of Correspondence: Dr. Moududul Haque, Associate Professor, Department of Neurosurgery, Bangabandhu Sheikh Mujib Medical University. Mobile: 01713042440, Email: moududneurosurg@gmail.com 
procedures involving calvarial vault remodeling. One of the more popular and well-described methodsis the $\mathrm{Pi}$ repair, first described by Jane et al in 1976. [3] Our procedureinvolves a modified Pi craniectomy [4] with barrel stave osteotomy.

\section{Case report}

A 25 months old female baby got admitted to our department with complaint of head disfigurement since birth. The head of the baby was small in size and asymmetrical at birth which gradually increased to attain the present size. Parents of the baby went to local govt. hospital for this problem and they were assured that the disfigurement would subside with time. The mother also noticed developmental milestone of the baby were delayed. She learnt to control her neck at the age of 1 year and still can't sit without support.

Four months back, her mother noticed enlargement of head antero-posteriorly and bulging anteriorly while shaving the hair of head of her child. She also mentions that her baby had reluctancy to feed, irritability and occasional vomiting. With above problems parents went to a private hospital and CT Scan of head was done which revealed hydrocephalus and left sided VP shunt was done there. No history of prolonged fever, trauma to head, convulsion or unconsciousness. Her bowel and bladder habits were normal.

Mother did not take any antenatal checkup during her pregnancy and baby was delivered at full term by NVD at home. Her postnatal period was uneventful. She has a younger brother of 11 months of age who is healthy. There was no familyhistory of craniosynostosis or craniofacial disorders. No history of consanguinity of marriage between parents.

On general examination, baby is conscious and playful. Systemic examination did not reveal any other congenital anomalies. Examination of head revealed occipito-frontal circumference was $44 \mathrm{~cm}$. Anterior fontanelle was open but posterior fontanelle was closed. Frontal bossing was present. There was reduced biparietal diameter [Figure $-1(a, b, c)]$. Left sided VP shunt was present which was functioning. There was no palpable bony prominence over the sagittal suture. There was no relative movement of the bones on firm pressure on either side of the suture. Neurological examination revealed no abnormalities.

CT scan of brain with 3D reconstruction showed sagittal suture is completely fused.[Figure $-2(a, b, c)$ ] Coronal suture is partially fused, but its impression is
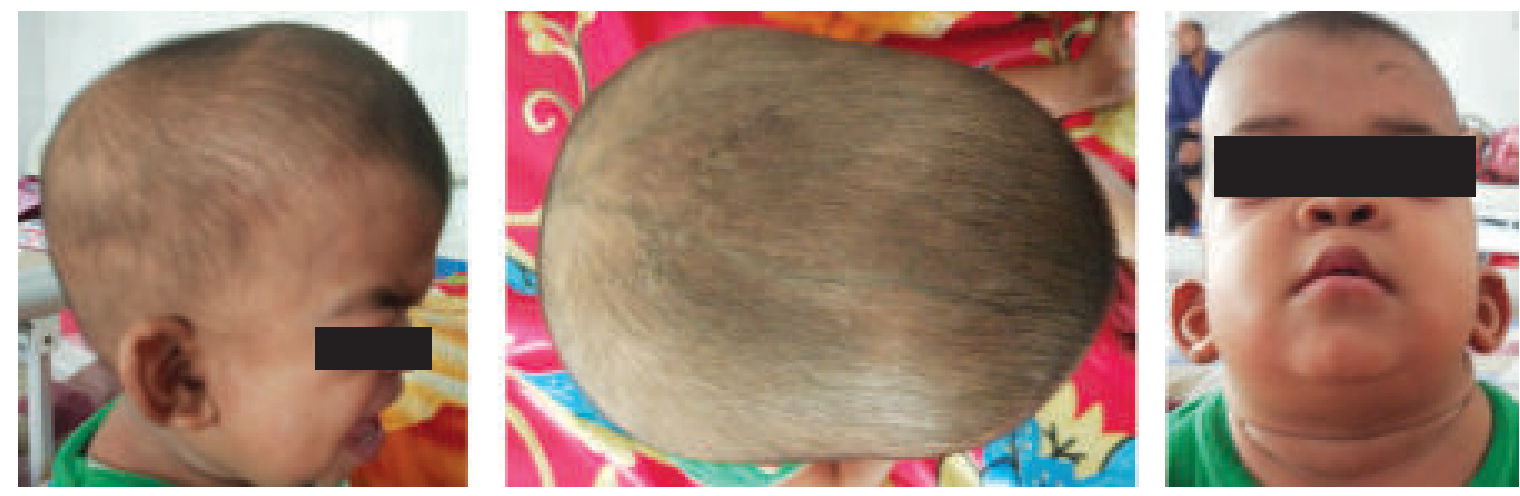

Fig.-1 (a,b,c): Abnormallyelongated skull (scaphocephaly)reduced biparietal diameter
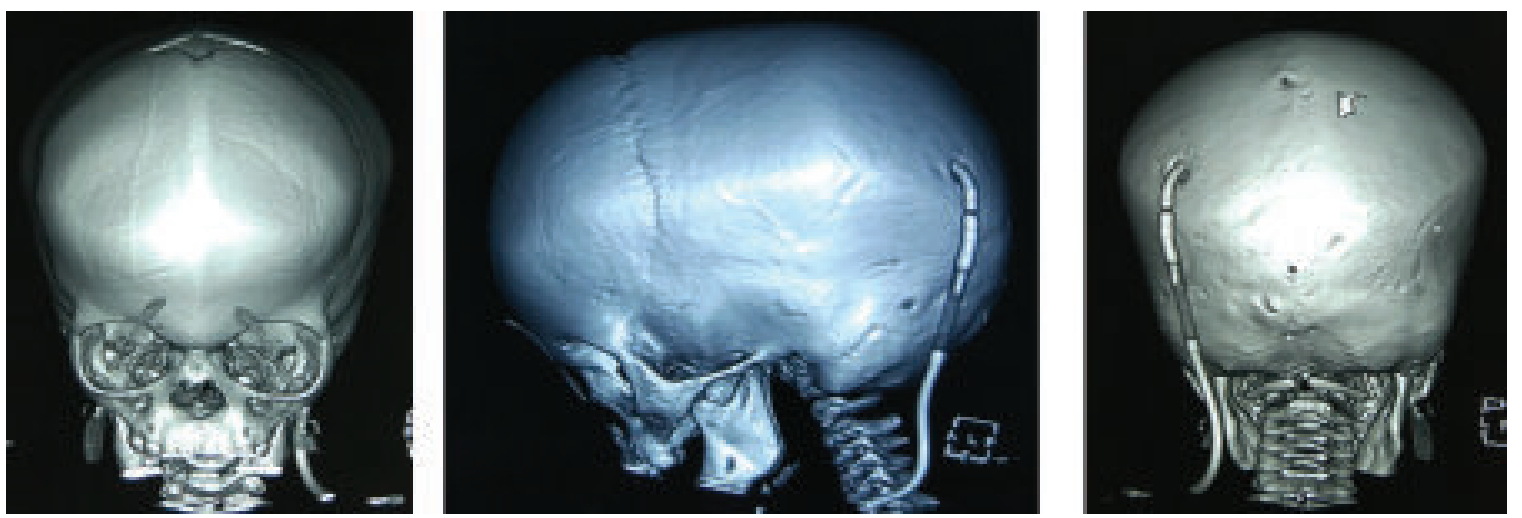

Fig.-2 (a,b,c): CT scan of brain with 3D reconstruction showed sagittalsuture is completely fused. 
still visualized. Anterior fontanelle is open, posterior fontanelle is closed. Frontal bossing is present. Left sided VP shunt is seen.

\section{Operative technique}

The baby was placed supine with head elevation to 20 -30 degree. Then she was wrapped with roll cotton to prevent hypothermia. Proper padding of pressure points was ensured. The zigzag incision was given halfway between the coronal and lambdoid suture. Zigzag skin incision decreases the visibility of the postoperative scar. Anterior and posterior flaps were raised in the subgaleal plane to supraorbital ridge anteriorly and lambdoid suture posteriorly [Figure 3]. Pericranium was left on the skull during scalp reflection to minimize blood loss.

The targeted areas of craniectomy were marked [Figure -4]. The horizontal bar of $\mathrm{Pi}$ was about $4 \mathrm{~cm}$ above

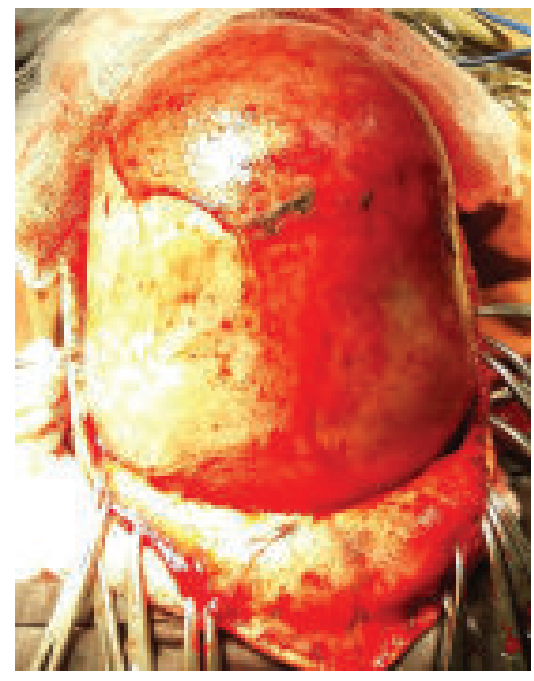

Fig.-3: (Anterior and posterior flaps were raised in the subgaleal plane)
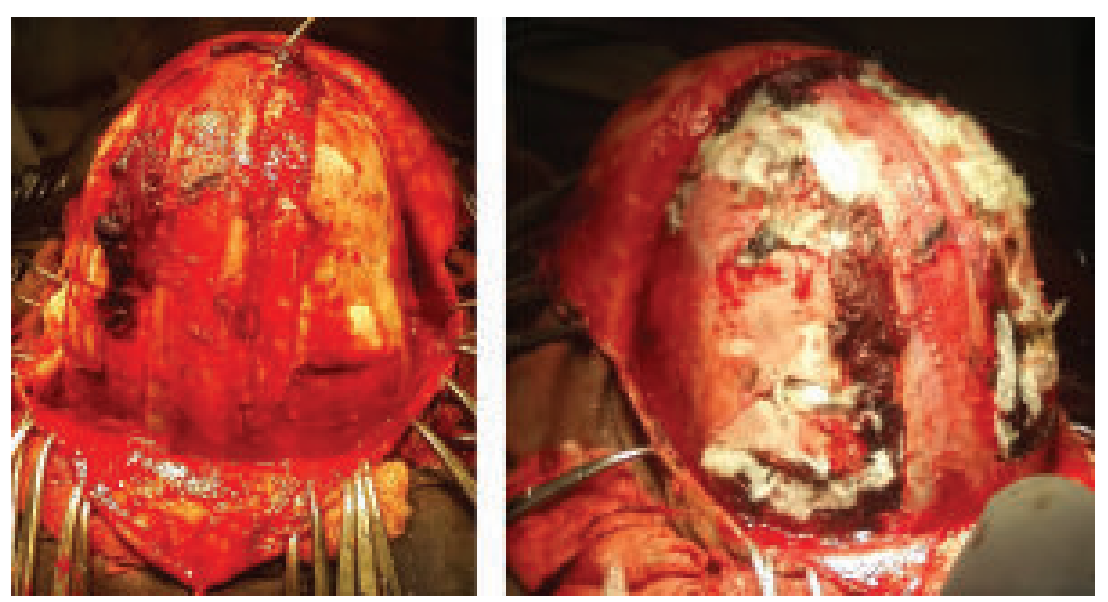

Fig.-5 (a,b): (Modified Pi procedure with barrel stave osteotomy) after 2 months. marked.)

the supraorbital ridge bilaterally and two legs of $\mathrm{Pi}$ was made along both sides of the sagittal suture, and ends anterior to the lambdoid sutures [Figure -5(a)]. Barrel stave osteotomies were then made [Figure 5(b)]. A sub-galeal drain was placed and the scalp was closed in layers. Intermittent blood transfusion was done during surgery, about $100 \mathrm{ml}$ of fresh blood was transfused peroperatively.Upon completion of the operation, the patient was extubated and were monitored in recovery room for 4 hours. Drain output was checked closely and postoperative hemoglobin level was checked on $1^{\text {st }}$ POD and $50 \mathrm{ml}$ blood was transfused. Next post-operative days were uneventful. Stitches were taken out on $7^{\text {th }}$ post-operative day [Figure-6]. A post-operative CT scan was done [Figure $-7(a, b)]$. A hear gear was given to the baby [Figure 8]. During discharge, parent were adviced to follow up

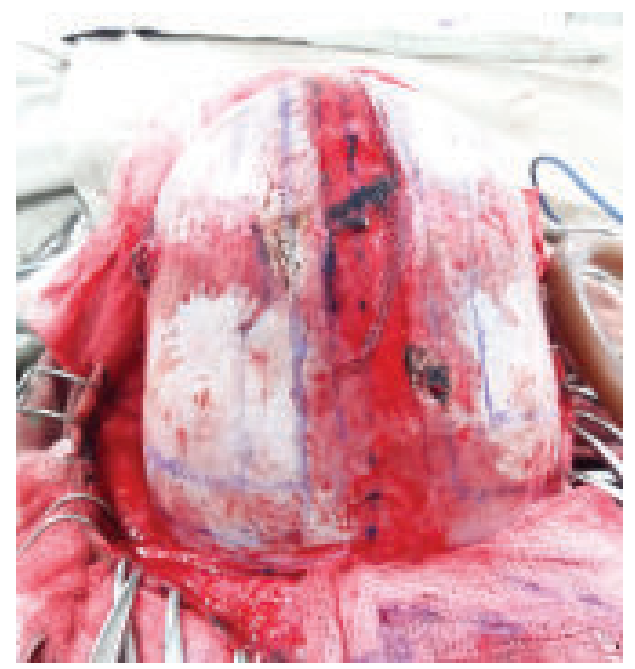

Fig-4: (The targeted areas of craniectomy were 


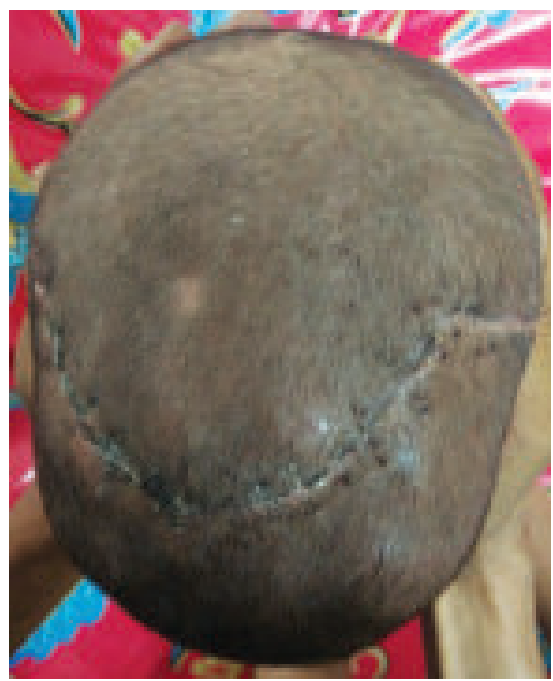

Fig.6: (well healed scar along the zigzag incision mark)
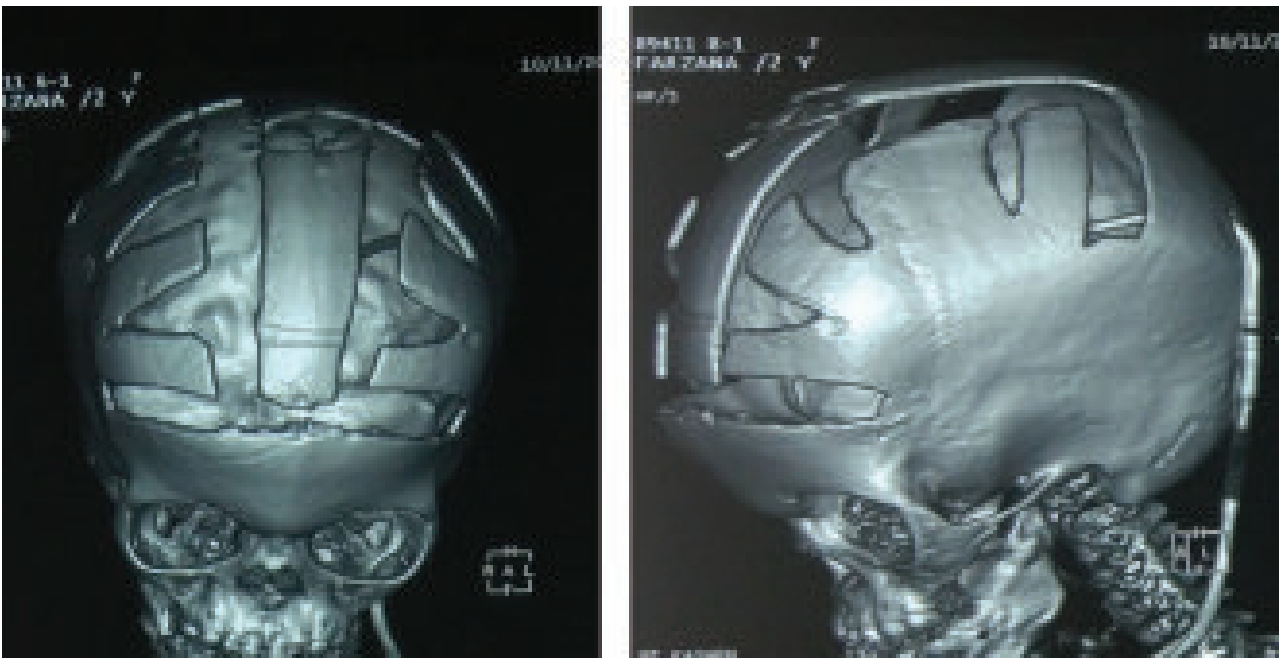

Fig.-7 (a,b): (post operative image shows osteotomy bone gaps)

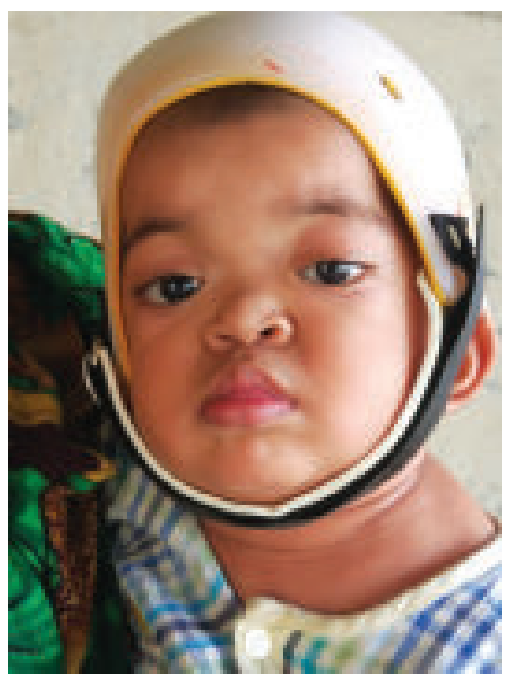

Fig.-8: A head gear was given to the baby (Reproduced with consent of patient) 


\section{Discussion:}

The premature synostosis of some of the cranialvault sutures causes expectable skull deformation and, in some cases, produces increased intracranial pressure. [5] Severe psychological effects of having of a disfiguring head is an important issue. [6] Different configurations of the skull are observed depending on the engaged suture. The premature synostosis of the sagittal suture or the sagittal craniosynostosis is the most frequentreason for a calvarial dysmorphology, requiringoperative correction.

The premature synostosis of the sagittal (interparietal) suture produces the typical scaphocephalic configuration with frontal and occipital bossing and small biparietal distance (reduction of the normal calvarial wide and acompensatory anterior-posterior extension). Ordinary, these deformations get worse with time.

That is why the purpose of the applied treatment is"normalization" of the head shape. The management of sagittalsynostosis (SS) is surgical, the 2 main aims being to normalize the aesthetic appearance of the skull, and to relieve increased intracranial pressure, thus providing a cranium of appropriate geometry and volume to allow for the normal development and growth of the child's brain.[7] As our understanding of thedisease process has evolved, and with the advent ofsurgical innovations, the operative approaches for managing patients with SS have considerably changed, ranging from the initial suturectomy as described by Lannelongue in 1890 and Lane

in 1892 to the more extensive calvarial vault remodeling and variants there of. More recently, the use of springassisted surgery and endoscopic-assisted craniectomies, with and without helmets as postoperative adjuncts, has been described. [8]
In comparison with the other techniques in the literature, the advantages of our technique are the fast and easy technique, the small risks of bleeding[9] and operative shock at its both stages, as well as the retaining of the bone protection of the sagittal sinus.

\section{Conclusion:}

If normalization of the head shape is the primarygoal of the performed operative treatment, weconsider that the proposed operative correction of the scaphocephaly is an part of the management of the sagittal craniosynostosis.

\section{References:}

1. Kolar JC. An epidemiological study of nonsyndromal craniosynostoses. J Craniofac Surg 2011;22:47-49

2. Barritt J, Brooksbank M, Simpson D: Scaphocephaly: aesthetic and psychosocial considerations. Dev Med Child Neurol 23(2):183-191, 1981

3. Jane JA, Edgerton MT, Futrell JW, Park TS: Immediate correction of sagittal synostosis. J Neurosurg 49(6):705710, 1978

4. Boulos PT, Lin KY, Jane JA Jr. et al. Correction of sagittal synostosis using a modified Pi method. Clin Plast Surg. 2004; 31:489-498. vii. [PubMed: 15219754]

5. Thomas GPL, Johnson D, Byren JC, et al. Long-term morphological outcomes in nonsyndromic sagittal craniosynostosis: a comparison of techniques. J Craniofac Surg 2015;26:19-25

6. Barritt J, Brooksbank M, Simpson D: Scaphocephaly: aesthetic and psychosocial considerations. Dev Med Child Neurol 23(2):183-191, 1981

7. Arnaud E, Marchac D, Renier D: Craniosynostosis and faciocraniosynostosis. Ann ChirPlastEsthet 42(5):443-480, 1997

8. Jimenez DF, Barone CM, McGee ME, et al. Endoscopyassisted wide vertex craniectomy, barrel stave osteotomies, and postoperative helmet molding therapy in the management of sagittal suture craniosynostosis. J Neurosurg 2004;100(5 Suppl):407-417

9. Meyer $\mathrm{P}$, Renier D, Arnaud E, et al. Blood loss during repair of craniosynostosis. Br J Anaesth.1993; 71:854-857. [PubMed: 8280553] 